\title{
Autism: Alterations in Auditory Perception
}

\author{
Pedro L. Nieto del Rincón \\ Universidad San Pablo-CEU, Madrid, Spain and Asociación Nuevo Horizonte Las Rozas de Madrid, Spain
}

\section{SYNOPSIS}

Investigations made in previous decades about irregularities in auditory perception in individuals with autism is reviewed and revised clinical and theoretical implications are provided. Emphasis is placed on the fact that these auditory perception irregularities of people with autism are very important for the understanding of the symptoms, for the search of its etiology, for the implementation of an adequate treatment program, and for the formulation of an adequate theoretical explanation of the syndrome.

\section{KEY WORDS}

autism; diagnostic; auditory perception; evoked potentials; brainstem, music; language

\section{INTRODUCTION}

The aim of this review is to describe the auditory alterations in autism and how they can be a key factor for a better theoretical description for the syndrome, for as an adequate diagnosis, and for correct treatment of people with autism. These auditory peculiarities led us to question again the important role of brainstem alterations in the etiology of the symptom of autism. It is necessary to have a holistic vision that takes into consideration sensorial modulation alterations controlled by the brainstem, as well as cognitive disturbances due to an incorrect development of upper cortical structures.

Accepted: 30 July, 2007

Reprint address:

Pedro L. Nieto del Rincón

Departamento de Psicología, Facultad de Medicina

Universidad S.Pablo-CEU, c/Tutor 35, $4^{\text {a }}$ planta

28008 Madrid, Spain

e-mail: pedroluisn@correo.cop.es
In people with autism the brain is structured in an unusual fashion and this can imply problems with social relationships. However, this can also permit enhanced performance in basic perceptive tasks, as in musical skills and others.

The study of perceptive alterations in autism seems to have been left aside for some years. This was partly caused by changes in diagnostic criteria, and also by new emerging theoretical approaches. But current research - which relies on more powerful and efficient tools, both statistical and neuroimaging, - underlines again the importance of perceptive deficits among people with autism. Any current theoretical explanation must bear these deficits in mind in order to provide a holistic explanation of both the etiology and the patophisiology of this syndrome.

An exhaustive bibliographical research has been carried out, as well as critical reading of the resulting material, in the light of different explanatory theories on autism. There are some recent reviews about some partial aspects of this question: In the review by Rogers and Ozonoff /116/, they reach the conclusion that sensorial symptoms are more frequent and outstanding among children with autism rather than among typically developed children, but there is no clear evidence that these symptoms make a clear difference in relation to other Pervasive Development Disorders (PDD). The review by Kellerman and Gorman /60/ states that auditory perception studies in individuals with autism find perceptive disorders which would be related to both language alterations and the social isolation observed among people with autism. The present review attemps be more hollistic and comprehensive.

\section{DIAGNOSIS OF AUTISMAND AND AUDITORY PERCEPTION ALTERATIONS}

Ever since Kanner /58/ diagnosed autism in 1943, one of the big practical difficulties when 
forming experimental groups was a reliable diagnosis of autism which would be accepted by all experts. The first diagnostic criteria included severe disorders on relationships, language, perception, motility and development /106/. Diagnosis based on experienced professionals' report used to be frequent $/ 105 /$. Afterwards, more standardized diagnostic criteria began to be used, such as the ones from the National Society of Autistic Children /115/, which evaluated social, perceptive and developmental disorders.

The change arrived with the DSM-III diagnostic criteria (/2/ and subsequent editions). Diagnostic criteria included communication disorders, social disorders, as well as disturbances of response to objects. This manual, which is used world-wide, implied a high degree of agreement among different researchers, and standardized experimental groups into the same diagnosis.

However, Ornitz and colleagues /101/ complained that sensorial modulation problems had been little acknowledged by the DSM-III criteria. They considered perceptive disorders very important in diagnosis of autistic syndrome. One of the possible reasons why perception disorders were not used as diagnostic criteria in this manual could lie in the fact that, although they are very common among younger children with autism (up to 4 years), they are not as intense and easily observable after this stage. Besides, brain and auditory exploration techniques were not as widely developed in 1980 as they are now. It was therefore very complicated to make sure that a child older than 6 years - who would very often refuse to cooperate suffered perception disorders.

In 1989 Ornitz complained again that sensorial deficits were still not be included in the manual's new version, DSM-III-R /1/; on the other hand, perceptive disorders were included in PDD criteria. Therapists working with people with autism often note their sensorial disorders. Some epidemiological studies, such as Ornitz's /97/ show the high prevalence of this kind of disturbance in this population: the parents of 242 people with autism completed a survey, and Ornitz /97/ found that 155 of the children with autism had sensorial modulation problems and 163 had social relationship problems as well as bizarre response to objects.
These two variables were significantly closely related and their extent matched the normal distribution. Exclusion of sensorial problems from the diagnostic criteria meant a radical change in the approach of research on hearing and autism. Such studies were very numerous in the first years, but after a few decades interest in this question diminished considerably.

However, the arrival of new research and exploration methods, as well as the first contrasted results that once more highlighted perception disturbances, favored a renewed interest in this field of research in the last years.

\section{REPORTED DISTURBANCES IN AUDITORY PERCEPTION}

In 1967 Metz /79/ proved that the people with autism that he studied preferred higher intensity auditory stimulation. Later, Hermelin and Frith /50/ confirmed the existence of perceptive faults which were not detectable in audiometric exploration. Such faults were: lack of response to sounds, inability to interpret auditory stimuli, and absence of orientation reflex to such stimuli. They describe how some people with autism cover their ears and others use contact senses - touch and taste - to explore objects, rather than sight and hearing.

Ornitz /99/ also observes the preference of contact senses and he found an apparent predominance of the visual over the hearing in some people with autism; this seems to be due to the inability to respond to various senses at the same time.

The investigation carried out by Reynolds and colleagues /113/ showed that when exposed to multiauditory stimuli, there appears to be a stimulus hyperselectivity that causes the people with autism who took part in their experiment to respond to only one key rather than the whole complex stimulus. Koegel and Schreibman /66/ found lack of response to sounds. Ornitz and colleagues /102/ described various and apparently contradictory responses to sensorial stimulation: hyposensitivity to sounds, enhanced awareness of all background sounds, and hypersensitivity to auditory stimuli, depending on each person and situation. Gersten /35/ found that some children with autism showed 
hyperselectivity. Abnormal auditory responses were common among the children with autism studied by $\mathrm{Xi}$ and colleagues /148/ who also found significant differences in auditory filtering.

Møller and colleagues /80/ reported a peculiar phenomenon. There are two kinds of auditory pathways: the classical ones, which carry only auditory input and end in the primary auditory cortex, and the non-classical ones - extra-lemniscal, slower and phylogenetically older - which end in the secondary auditory cortex. In children without disorders, the perception of sound intensity is altered by simultaneous electric stimulation on the medium nerve of the wrist. This modal interaction fades during childhood and is rare after 20 years old. But in the group of adults with autism studied by Møller and colleagues $/ 80 /$, this phenomenon was more intense and persisted with age. This would support the idea that some individuals with autism have abnormal intermodal interactions between the auditory and somatosensorial systems. They suggested that their results might indicate immaturity in the hearing system of people with autism. In the cross-sectional study of Kern and colleagues /62/ it was concluded that persons with autism had abnormal auditory processing that was significantly different from that in controls.

\section{HYPOACUSIS AND HYPERACUSIS IN PEOPLE WITH AUTISM}

Among the exclusion criteria of experimental participants, associated auditory deficits are often found in early research. This criterion is correct from the point of view of control of experimental variables. However, some valuable information on co-morbility of autism and hearing deficits was lost. Little by little researchers noticed the importance of this kind of information, and either they continued to exclude participants with associated hearing deficits - but provided information on their number - or they investigated this aspect - comorbility - directly. Some clear-cut data then appeared, indicating a prevalence of hearing deficits among the population with autism, which was remarkably high (even as regards obvious hypoacusis and deafness): Among the 14 children studied by Hayes and Gordon /44/, 13 of them presented variable deafness and unusually high acoustic thresholds; the other child had otitis media. Out of the 32 children studied by Taylor and colleagues /138/, 11 had moderate hearing loss (eight on both ears) and three had severe to deep hearing loss (all three in both ears). In the study carried out by Smith and colleagues /130/, the people with autism presented remarkably worse medium ear impedance values. In a review in 1993, Klin /64/ reached the conclusion that in the studies of brainstem auditory evoked potentials, some data were found suggesting peripheral hypoacusis. It would be worth noting the investigation by Rosenhall and colleagues /119/ in which a large group of 199 children with autism (153 boys and 46 girls) was audiologically assessed. They found hypoacusis media or moderate in $7.9 \%$ of the studied group. They too found unilateral hearing loss in $1.6 \%$ of all the children that could be properly assessed. Severe to deep bilateral hearing loss was found in $3.5 \%$ of the patients. This represents a remarkably higher prevalence in relation to the general population, and comparable to the prevalence found in samples of people with intellectual handicaps. In this detailed study, hearing deficits appeared in the same proportion in all intelligence levels of the sample of 199 children with autism, so it does not seem that intelligence variability may account for autism hearing deficits. Hypoacusis was common and affected $18 \%$ of the group under study (they did not tolerate click sounds at $80 \mathrm{~dB}$ and they had to be assessed at 70 $\mathrm{dB})$. No hypoacusis was found in the control group. In addition, the proportion of serous otitis media $(23,5 \%)$ and its related conductive hearing loss $(18,3 \%)$ seemed to be higher in the group of people with autism in comparison with the control group.

In the light of these results, Rosenhall /119/ logically insists on the need of auditory screening in people with autism so that individuals with severe hearing loss can have aural habilitation; he also points out that people with moderate to slight hypoacusis should be followed, owing to the risk of progressive hearing damage. Rosenhall and collegues $/ 118 /$, in a further study, had to discard 52 out of 153 participants because they had definitive hearing deficits. Another detailed French study carried out by Gayda and Saleh /34/ in the Íle de 
France region must also be borne in mind: 500 children with autism were included and they found that $15 \%$ of children aged from 11-13 years had hearing problems. However, Gravel and colleagues 139/ did not found auditory difficulties in persons with autism.

But not all is hypoacusis. Clinical hypersensitivity to sounds among people with autism has frequently been described: In a study by Mottron and colleagues $/ 85 /$ an adolescent with great musical ability was under study. Apparently QC had been hypersensitive to sounds since childhood. His extraordinary hearing capacity was proved at the age of 13 years by audiometry that determined the following: he was able to hear with his right ear sounds ranging from $1,500-5,000 \mathrm{~Hz}$ at $15 \mathrm{~dB}$ under the normal hearing threshold, and with his left ear sounds ranging from $1,000-4,000 \mathrm{~Hz}$ at 10 $\mathrm{dB}$ under the normal hearing threshold.

In an interesting investigation, Collet and colleagues /16/ studied hyperacusis and explained that in disorder-free people this phenomenon was related to some alteration of their medial olivocochlear (MOC) bundle functioning. The easiest and non-invasive way to study MOC functioning is to associate contralateral stimulation and evoked otoacoustic emissions (EOAE). They found that the contralateral suppression effect was inferior in people with autism. The explanation for this can be the diminishing of the MOC bundle functioning in autism. This breakthrough was very relevant in the brainstem lesion theory /100/, as the MOC belongs to this anatomical structure.

This data on hearing deficits in people with autism suggested the hypothesis that auditory sensorial deprivation might cause autism. However, the results of Jure and colleagues /57/ in an epidemiological study carried out among 46 children with both hearing disability and autism disproved this hypothesis for two reasons: firstly autism is not frequent in children with hearing disabilities and secondly, in their sample, no correlation was found between the degree of autism and hearing loss severity. They concluded that both syndromes have different etiologies. But certain diseases such as rubella could damage both the brain and the ear, and might be the cause of both diseases in some cases. Behavioral auditory test measures were carried with this population of children with autism by Tharpe and colleagues $/ 141 /$, who found behavioral pure-tone averages outside the normal hearing range (i.e., $>20 \mathrm{~dB} \mathrm{HL}$ ), despite having normal to near-normal hearing sensitivity as determined by other audiometric measures. Hearing loss may be more common in children with autism than in normally developing children /137/, and Jure and colleagues /57/ suggest that audiometries be carried out in all children with autism. Grewe and colleagues /40/ suggested that transient-evoked otoacoustic emissions (TEOAEs) might be a valuable part of the audiologic test battery for children with autistic behavior.

\section{FINDINGS RELATED TO THE BRAINSTEM}

Many areas of the brainstem are important in hearing /131/ and are especially vulnerable to perinatal injury. These structures are some of the first to develop in the fetus's brain. Apparently, neurochemical changes in the maturation of the hearing system can stimulate the growth of cerebral cortex upper centers /126/. The brainstem structures, particularly the inferior colliculus, need a high supply of oxygen and are very sensitive to anoxia. As they are already covered with myelin at birth a lesion does not usually heal easily. These structures included in the tectum are related to selective attention and stimulus orientation /127/. Myelinization in the hearing system occurs between the $26^{\text {th }}$ and the $29^{\text {th }}$ week of pregnancy. It is in this stage that the first responses to sounds appear. This early maturation of the hearing system produces both chemical and neural changes which stimulate maturation in the upper cortical areas /126/. It seems that enkephalins are produced in the brainstem nuclei and are involved in the sensation of pleasure, in motivation, and in pleasurable and emotion evoking effects as regards music /126/.The auditory system can be easily damaged by perinatal oxygen insufficiency $/ 24,87,110,133 /$. Yakovlev and Lecours /148/ found that the auditory system is fully myelinated before birth, and Moore and colleagues /81/ confirmed the early myelination of the auditory system. Landau and colleagues /67/ and Sokoloff /132/ studied blood flow in the brain and found the most intense activity in the inferior 
colliculus, the superior olive, and nuclei of the lateral lemniscal tracts that connect the brainstem auditory nuclei.Records of the brain's blood flow and glucose utilization reveal that the brainstem nuclei are the ones with the highest degree of metabolic activity in the brain. Therefore, they are far more sensitive to any blood flow difficulty, such as anoxia or lack of glucose, which may be caused by any perinatal illness or infection /126/. Ornitz and colleagues /106/ found a lesser inhibition in sensorial respon-ses associated to eye movement. This inhibition is controlled by the vestibular system, and this suggests a disorder in this system - in the brainstem - in people with autism. Quite a few of them show-ed diminished post-rotational nystagmus. Ornitz /99/ and Ornitz and Walter /103/ reported atypical responses in the vestibular system.

In 1989, Ornitz /96/ described the malfunctioning of the reticular formation in the brainstem, which could provoke asynchrony in the response rate of the heart. A weak modulation in sensorial inputs could cause exaggerated autonomic responses to auditory stimuli. Ornitz /96/ suggested that excessive reverberation in the neuronal loops of the brainstem's synaptic pathways could be the reason for such exaggerated autonomic responses, as well as disturbances in muscular tone. All this suggests a possible disturbance in the descendent control that the brainstem exercises over spinal mechanisms. The following structures in the brainstem would be involved: the reticular formation, substantia nigra; both specific and non-specific thalamic nuclei; rostral projections of these structures into the neostriatus and cortical structures.

In 2001, Khalfa and colleagues /63/ investigated the medial olivocochlear system's auditory filter: the evoked potentials' amplitude decreases when the contralateral ear is stimulated with noise, owing to the medial olivocochlear system's auditory filter. People with autism had a larger suppressive effect in the right ear than in the left ear. This asymmetry did not appear in the controls. This suggests a failure in the medial olivocochlear system in people with autism.

\section{EEG STUDIES}

The electroencephalogram (EEG) is a noninvasive and relatively cheap way of investigation. It offers very accurate temporal resolution - which modern neuroimaging techniques cannot yet reach but its spatial resolution is very poor. Apart from this, in the first studies very few electrodes were used, so the spatial resolution was even worse. If the alterations caused by light and sound in EEG waves are added to an EEG study, the result is a study of evoked potentials. Auditory evoked potentials have been widely used in research on autism. Evoked potentials are divided into two types: obligatory evoked potentials, in which people are passive and they only listen - be they either asleep or unconscious: the secomnd is cognitive evoked potentials, in which people are requested to give a specific response to the target stimulus - which appears with a probability of $80 \%$ - and to ignore another unusual stimulus - which appears with a probability of $10-20 \%$.

\section{Obligatory auditory evoked potentials}

In studies dealing with brainstem evoked responses, up to seven waves have been registered but only the first five are usually studied (I, II, III, IV and V). These responses are commonly called auditory brainstem responses (ABRs). It is considered that wave I is generated by the first afferent auditory brain cell in the most distal part of the auditory nerve, in the cochlea; wave III is generated in the ipsilateral cochlear nucleus; and wave V is generated in the lateral lemniscus, but many other anatomical structures are also involved /118/. Most of these waves are generated by structures situated in the brainstem. Interpeak latencies (I-III; III-V and $\mathrm{I}-\mathrm{V})$ reflect the functioning of the auditory pathways $/ 120 /$. The I-III interpeak latency represents the activity of the first auditory nerve's brain cell. The III-V interpeak latency represents the auditory system's conduction time, within the brainstem, from the cochlear nucleus to the oliva in the lateral lemniscus. The I-V interpeak latency represents total auditory neural conduction time from the auditory nerve's most distal part to the oliva in the lateral lemniscus, that is, the total conduction time of auditory information /118/. 
Most studies have come to the conclusion that waves I, II, III, IV and V have a lesser amplitude, that is, are weaker, among people with autism /37, $64,72,73,105 /$, but a few studies $/ 25,41 /$ did not find any significant differences. Most studies conclude that these waves have also a greater latencie $/ 37$, $117,123,131,135 /$, although other studies /25,41, 134/ found no significant differences.

In these first studies only absolute latency and amplitude of waves I, II, III, IV and V were assessed. Some present methodological faults such as inadequate diagnostic criteria, poor auditory assessment, inadequate control groups, muscular artifacts and badly described co-morbid diseases /120/. In two of them /72,73/ it was stated that people with autism show less habituation to repetitive auditory stimuli and they even become more sensitive to them. This matches the observations that some children with autism seem to be deaf to powerful noises of short duration (such as a door slamming), whereas they do not seem to tolerate less intense but persistent stimuli such as the toilet flush noise or a vacuum cleaner humming. Research dealing with transmission times I-III; III$\mathrm{V}$ and I-V eventually agreed on their disfunctionality, as observed by Klin's review in 1993 /64/.

Latency has been reported as follows: I-III higher latency $/ 76,118,120,136,137,138 /$; Maziade and colleagues /76/ found such higher latency also in first-degree relatives of 73 children with autism. III-V higher latency $/ 118,128,129,136,143 /$; however, in the study by Rumsey and colleagues /120/, latency III-V was lower with rarefaction clicks. I-V higher total latency $/ 78,118,128,129,131,135,136$, $138,143,147 /$. In the study by Courchesne and colleagues $/ 17 /$ no remarkable differences were found in any of the latencies I-III, II-V and I-V. Most of these studies dealing with obligatory waves were carried out with relatively high intensity sounds. It is worth mentioning the study by Tanguay and colleagues $/ 136 /$, who used sounds at different intensity and found more problems related to weaker intensity. This relationship between a lesser sound intensity and larger alterations in the responses of the brainstem matches once more the clinical observation according to which people with autism respond better to high acoustic stimulation. All these data relating to obligatory auditory evoked potentials lead to the consideration of the possibility of either genetic or acquired damage of the auditory processing structures in the brainstem.

\section{Cognitive auditory evoked potentials}

The interpretation of cognitive auditory evoked potentials is more complex, as we must bear in mind the attentional and motoric processes that complicate the inferences to be obtained from experimental results. The literature on cognitive evoked potentials in autism is quite wide, although its results are somewhat variable, possibly due to the different methodology applied in each study and to the setting of the experimental and control groups used.

The first study on this issue was that by Ornitz and colleagues /104/ who registered auditory EEG responses during sleep (with only three electrodes). No significant differences were found among different groups. However, later, Ornitz and Walter /103/ found differences depending on the sound's phase. People with autism showed a significantly larger tendency to respond out of phase when exposed to the two different sounds, namely, condensation and rarefaction. The condensation phase is named thus because air molecules are compressed in this moment and the condensation phase is named thus because the molecules are separated.

The name of different cognitive evoked potentials are based on two aspects: wave polarity (either positive or negative) and average latency (within a relatively wide latency range). For instance, the P100 wave has a positive polarity with a latency of $100 \mathrm{~ms}$, and the N100 wave has negative polarity and begins $100 \mathrm{~ms}$ after the acoustic stimulus.

The most studied wave is the P300: It has been found that the P300 or P3 shows a lower amplitude (i.e. with less intensity) among people with autism $/ 19,74,75,89,92,140 /$. In the study by Courchesne and colleagues $/ 19 /$, a lower amplitude was found in the $\mathrm{A} / \mathrm{Pcz} / 300$ wave (positive wave of $300 \mathrm{~ms}$ of latency, registered in the $\mathrm{Cz}$ electrode as a response to auditory stimuli) and in the A/Ncz/800 wave (negative wave of $800 \mathrm{~ms}$ of latency, registered in the $\mathrm{Cz}$ electrode as a response to auditory stimuli). 
These results were later confirmed by Kemner and colleagues /61/. Oades and colleagues /92/ have also found a greater latency in the P3 wave, mainly to target stimuli in the right parietal. People with autism were more sensitive to the physical traits of the stimulus (for instance the tone of unusual stimuli) and its association with a meaning was inferior (e.g.: P3 in response to target stimulus). Both precocity signs (right dominance for P3) and developmental delay (below top P3 levels in the parietal) appeared.

Many other studies have confirmed a lower amplitude in the N100 or N1 wave $/ 12,14,90,91$, $122,140 /$. Bruneau and colleagues /14/ interpret this as hypersensitivity, as these people show a limited response even to weak stimuli; Lincoln and Courchesne /69/ believe that this is congruent with Ornitz's theory $/ 100 /$, dealing with lack of sensorial modulation.

Researches agree on the fact that the P200 or P2 wave is of lesser amplitude /14,74,75,90,91/. Regarding the lower amplitude of the P100 or P1 wave, the few studies there are agree $/ 14,74,91,92 /$. As far as latency in the N1 wave is concerned, there are two contradictory studies: Oades and colleagues 192/, who reports shorter latencies and Seri and colleagues /122/ who report a notably longer latency. There is only one study on augmented N200 or N2 amplitude: Ornitz and colleagues /106/ in the REM phase. The only difference that Courchesne and colleagues $/ 18 /$ found was an augmented SW latency for target sounds in people with autism. They define the SW wave as the top positive peak in $\mathrm{Pz}$ after a $\mathrm{P} 3 \mathrm{~b}$ wave with maximum amplitude in $\mathrm{Cz}$ or $\mathrm{Pz}$.

Another cognitive evoked potential wave has been recently studied in the recent years: the MNN (MisMatch Negativity). Gomot and colleagues /38/ believe that the processes involved in the detection of changes in auditory stimuli can be measured by means of the MNN. Supposedly, this response is generated by a comparison process between the new stimulus and the frequent repetitive stimulus's trace. The interesting wave density maps obtained in this recent study showed great differences between groups of people with autism and associated disorder-free people: The MNN waves in this latter group showed great negativity in central areas, mainly in $\mathrm{Fz}$, which is associated to bilateral positivity in temporomastoides sites. People with autism show similar mastoideal positivity but the frontal negativity showed bilateral distribution in frontal areas, with maximum peaks in the $\mathrm{C} 3$ and $\mathrm{C} 4$ electrodes. Temporal activity started earlier in people with autism. Theses topographic differences indicate differences in the brain mechanisms involved in the detection of new stimuli. JanssonVerkasalo /54/ and Jannson-Verkasalo and colleagues /56/ found greater latency in a MNN wave for syllables and tones in both hemispheres in people with autism. The MNN wave for syllables showed greater amplitude in the right hemisphere in people with autism and a greater amplitude in the left hemisphere in the control group. People with Asperger syndrome also showed difficulties in auditory processing, and this has been proved by augmented MNN latencies. The delay in the MNN wave was greater in the right hemisphere, especially for tones.

Kemner and colleagues /61/ found auditory cognitive evoked potential waves in occipital areas - generally associated to sight. This effect could be the first evidence of a peculiar distribution of cortical functions related to perception in people with autism.

Extreme care is needed when drawing conclusions from these studies owing to their implications in the field of attentional cognitive processes. But all of them allow us state that the processing of auditory information, its detection and related decision making can be altered also in people with autism. It is worth noting that the peculiar distribution of evoked potentials and their lesser amplitude matches the clinical observations of lesser attentional intensity and persistence in people with autism. Recently Jansson-Verkasalo and colleagues in a study dealing with cognitive evoked potentials /55/ found a similar atypical decodification of sounds in both children with Asperger syndrome and their parents.

\section{ANATOMICAL NEUROIMAGING STUDIES}

Hashimoto and colleagues /43/, using magnetic resonance imaging (MRI) found morphological alterations in the brainstem and cerebellum of 102 
adults and children with autism. Although the cerebellum and the brainstem grew with age in both children with autism and the control group, these structures were significantly smaller in children with autism. They suggest that alterations in the brainstem and the cerebellum in people with autism are caused by early lesion and hypoplasia, rather than by a progressive degenerative process.

Neurodevelopmental research suggest problems in neuronal proliferation, migration and organization that produce alterations in the cerebellum, brainstem, limbic system and the temporal lobes of people with autism. Larger than usual brain cells have been found in the septum, cerebellar nuclei and the olive /139/ of persons with autism.

\section{FUNCTIONAL NEUROIMAGING STUDIES}

It should be clarified that many functional neuroimaging studies examine only highfunctioning individuals. This raises the question as to whethr these findings can be generalized to lower functioning individuals.

Bruneau and colleagues /13/ used transcranial Doppler (TCD), a non-invasive technique that offers the possibility of studying the working brain. It showed disorders in blood flow functional distribution when hearing an auditory stimulus. A stable pattern related to changes in the blood flow in response to tone was observed in disorder-free children. The flow increased and resistance indexes diminished in the left hemisphere. The same pattern, although less strong, also appeared in the intellectually weak group of children. However, the response pattern in children with autism was different: their response to the auditory stimulus was symmetrical in the two hemispheres: blood flow diminished and the resistance index increased in both hemispheres.

In contrast, Garreau and colleagues /33/ measured the regional cerebral blood flow (rCBF) using single-photon emission Computed tomography (SPECT) during resting time and during binaural auditory stimulation. No cortical disorders in blood flow were found in people with autism.

Müller and colleagues /86/, using positron emission tomography (PET), examined brain organization as regards language, and studied brain flow in repose, listening to tones, as well as repeating and generating sentences. They found that people with autism showed: (a) inverted hemispheric dominance during auditory verbal stimulation; (b) a tendency to reduce auditory temporal cortex activation during acoustic stimulation; and (c) reduced cerebellar activity during non-verbal auditory perception and also possibly during expressive language. Müller and colleagues /86/ concluded that these results are compatible with former findings related to cerebellar disorders and such findings might suggest a tendency to atypical dominance for language in people with autism. Magnetoencephalographic measurements of mismatch field (MMF) studies have revealed glucose metabolic disturbances in temporal, frontal and parietal associative cortex and also disturbed serotonin synthesis /139/. Boddaert and colleagues /7,8/ in two PET studies with both adults and children with autism respectively, found temporal hypoperfusion in repose. In associated-disorder free participants, these brain regions are activated when listening to sounds similar to spoken language. In addition, a disturbed hemispheric activation pattern was found in people with autism: the right frontomedial gyrus (Brodmann areas 9, 9/46 and 10) showed greater activation in people with autism. The left temporal areas (Brodmann area 21) showed lesser activation in people with autism. No sulcus temporal superior (STS) activation was found in children with autism. However, unrelated areas, such as the cyngulus, parietal lobe, brainstem and cerebellum, were activated. They concluded that this kind of distorted auditory cortical processing is involved in both language disorders and inadequate responses to sounds, typically observed in people with autism.

In a study using functional MRI (fMRI), Gervais and colleagues /36/ showed that people with autism fail to activate voice selective brain regions of STS in response to vocal sounds, whereas a normal activation pattern in response to non-vocal sounds was shown. According to these authors this suggests qualitatively different cortical processing of socially relevant auditory information.

Tecchio and colleagues /139/ used magnetoencephalography (MEG). More specifically, they measured the MMF which is the electromagnetic 
equivalent to the MNN wave. The associateddisorder free participants showed a clear MMF with a M100 brain wave whose latency, position and amplitude were clear. However, people with autism showed no identifiable MMF wave. These findings suggest that low-level people with autism have a disorder in preconscious stages of auditory cortical discrimination, which plays an important role in the disturbed processing of auditory sensorial afferent information. Also using MEG, Gage and colleagues 132/ checked that alongside development the M100 wave latency diminished in associated-disorder free people with a ratio of $-4 \mathrm{~ms} / \mathrm{year}$ in the left hemisphere and $-4,5 \mathrm{~ms} /$ year in the right hemisphere. In people with autism, in contrast, not only did this M100 latency not diminish in the right hemisphere but it increased slightly with age $(0,8$ ms/year). These results provide us with evidence of different development in the auditory system in children with autism that reflects disturbances in their cortical development processes. In another study, Gage and colleagues /31/ did some research on the response range of M100 wave according to the frequency of the tone given. They found that the response range was far more reduced in the right hemisphere. They reached the conclusion that frequency decodification mechanisms can show a different developmental course in the autistic spectrum.

Finally, Oram-Cardy and colleagues 193, 94/ studied auditory responses in people with autism by means of MEG: latencies M50 and M100 do not differ in children with autism, but they showed a greater MMF latency. They concluded that difficulties in sound analysis can lead to an inadequate acoustic or phonological representation. This could cause language disturbances in the autistic spectrum.

\section{HEMISPHERIC PROCESSING ASYMMETRY}

Clear differences in the functional specialization of both brain hemispheres appear during the developmental process. It has been investigated whether such specialization appears also in people with autism. Results deny this hypothesis: Blackstock's $/ 6 /$ results indicated that some children with autism process predominantly with their right hemisphere. Prior and Bradshaw /109/ suggest that verbal functions develop in the right hemisphere of some people with autism, as they do not seem to show the characteristic right ear preference that disorder-free children show in dichotic hearing studies. In adittion, excess of left-ear preference for verbal sounds appears in children with autism. Wetherby and colleagues /146/ found such right ear preference only in echolalic people with autism. Tanguay and colleagues /136/ found differences in III-V and I-III transmission times between the two hemispheres that did not appear in people without associated disorders. James and Barry /53/ found delay in the development of brain dominance in children with autism.

Bruneau and colleagues /13/, in Doppler studies in children with no associated disorders, observed increased blood flow speed in the left hemisphere in response to auditory stimuli, whereas the response was symmetric in people with autism. Müller and colleagues /86/ found inverted hemispheric dominance during auditory verbal stimulation in a PET study. Khalfa and colleagues /63/ describe differences in peripherical auditory lateralization. Gomot and colleagues /38/ report atypical activity in the left frontal area in children with autism in response to acustical stimuli. Rosenhall and colleagues $/ 118 /$ found brainstem interhemispheric auditory latency differences in $18 \%$ of people with autism with normal hearing.

Jansson-Verkasalo and colleagues /56/ found greater latency of MNN in the right hemisphere for syllables and tones in people with autism. MNN for syllables was of greater amplitude in the right hemisphere in people with autism and of greater amplitude in the left hemisphere of disorder-free people. Gage and colleagues /32/ found that the M100 decreased with age in both hemispheres in the control group. This did not happen in the right hemisphere of people with autism. Gage and colleagues $/ 31 /$ found that the M100 response range of frequency modulation in children with autism was far more reduced in their right hemisphere.

Boddaert and colleagues /8/, in a PET study, found greater activation in the right hemisphere of people with autism and the opposite pattern in the control group. The right frontomedial gyrus showed more activation; and the left temporal areas showed 
less activation in people with autism. Flagg and colleagues /27/ have recently found in a MEG study concerning hemispheric lateralization development that children with autism and disorder-free children follow different developmental paths in language lateralization. A right lateralization tendency was more apparent in children with autism as they grew older.

\section{AUDITORY PERCEPTION OF EMOTIONS IN THE HUMAN VOICE}

Mottron /82/ stated that the voice can be regarded as auditory analogue of the face, as it constitutes a vehicle for social emotions both in production (expression of happiness, rage and worry through the voice) and reception (emotion identification in other people through crying, laughter, etc.). Like the face, it also constitutes an identity marker, since a person can be recognized by listening to his or her voice.

Hobson and colleagues /52/ found that people with autism performed better in non-emotional auditory tasks and worse in emotional ones. Klin /65/ asked children with autism to choose between their mothers' voices and some noise consisting of mixed voices recorded in a bar. The children of the control group prefer their mothers' voices. Children with autism either prefer the mixed noise or showed no special preference. This suggests some kind of disturbance in the infants' normal preference for the human voice. Later, the same results were found in another study /64/.

The group of people with autism studied by Loveland and colleagues /71/ performed worse in a matching detection task between faces and voices. However, in another study, Loveland and colleagues /70/ found no differences according to diagnosis but to intelligence. On the other hand Boucher and colleagues /11/ found once more that people with autism matched voices to faces worse than disorder-free people. Belin and colleagues /5/ state that the selective regions for the voice can be placed bilaterally in the upper segment of the central area in the STS. From these data Gervais and colleagues $/ 36 /$, using fMRI, found that people with autism did not activate the STS in response to vocal sounds, whereas activation was normal in response to non-vocal sounds.

\section{PROSODIC PERCEPTION AND PRODUCTION}

As regards the other people's voice prosody identification, investigators $/ 51,107,121,144 /$ found deficits when naming emotions expressed vocally. Boucher and colleagues $/ 10 /$ did not find this same result, but the methodological problem of this study lies in the fact that the people with autism were being trained to name known voices and the group of children with a specific speech disorder was not.

In relation to the prosodic expression of the people with autism themselves, the investigators $/ 4$, $26,31,107,127 /$ found a clear misfunction which, according to the latter, is due to some kind of maturation deficit in the right hemisphere. In a fMRI study examining the neural circuitry underlying deficits in understanding irony, Wang and colleagues /145/ found that children with autism spectrum disorders have difficulty interpreting the communicative intent of others. Ricks /114/, showed that the mothers of children with autism did not identify the meaning of their children's mumbling. A later study by Sheinkopf and colleagues /124/ showed that children with autism did not have any difficulty in uttering well-formed syllables (that is, normal mumbling), although they showed clear deficits in prosodic expression and difficulties in the vocal quality (that is, atypical phonation: falsetto voice, excessively high or low tones, diplophony and excessively high volume).

The group of children with autism studied by Shriberg and colleagues /125/ made more articulatory mistakes, incomprehensible sentences due to restrictions in their speech and inappropriate sentences in expressiveness, emphasis and resonance. Prosody problems in people with autism lay mainly in the prosody's pragmatic and affective aspects, whereas grammatical aspects remained relatively unaltered. In a review on the literature on autism and prosody, McCann and Peppé /77/ state that part of the findings have been contradictory due to the fact that each group of researchers has defined prosodic aspects using different criteria. 


\section{LANGUAGE PERCEPTION}

In 1970, Frith /30/ found that people with autism had problems remembering word sequences. Simon /127/ formulates the hypothesis that people with autism loose the ability to imitate a language 'by ear' and learn it as a mother tongue too early. Apparently, they learn their first language in the same way as adults learn a foreign language. Hayes and Gordon /44/ found that people with autism were able to identify noises, but not spoken language.

Dawson and colleagues /21/ found that the P3 amplitude to phonetic stimuli correlated to speech ability, that is, a small P3 amplitude to chords or to phonetic stimuli indicated poor speech. The PET study by Müller and colleagues /86/ suggests some sort of atypical dominance for language in autism. Rapin and Dunn /111/ reached the conclusion that there are disturbances in the neural processing of words in the lateral superior temporal gyrus. There is also evidence of disturbed neural processing of semantic information. The $\mathrm{N} 4$ does not show the usual increase in response to the deviation of the semantic context in people with autism /23/. This might reflect a flaw in the selective activation of word meaning by the semantic context. JanssonVerkasalo and colleagues /54/ found a greater latency and amplitude MNN in the right hemisphere in response to syllables and tones. Ceponiéne and colleagues $/ 15 /$, when studying a group of highlevel people with autism, found an orientation reflex that was specifically eliminated for speech sounds, even though the processing of such stimuli was correct. Boddaert and colleagues /8/ found an unusual hemispheric activation pattern for speech sounds: greater activation in the right hemisphere among people with autism and in the left hemisphere among disorder-free people. Finally, Lepistö and colleagues $/ 68$ / found that involuntary orienting to sound changes, as reflected by the P3a, was more impaired for speech than non-speech sounds in the children with autism.

From all this data one might conclude that speech perception is altered in people with autism; this hypothesis is partly hindered by the previously studied auditory disturbances. Recently Kasai and colleagues /59/ found evidence of delayed latency in phonetic MMF in adults with autism. According to them, this would mean that autism is associated with delayed processing in automatic changes of speech sounds. The study of Gunji and colleagues /42/ found deficits in speech audio feedback in children with autism that could be one of the reasons for their delay in speech development. Finally, in the above-mentioned MEG study by Flagg and colleagues $/ 27 /$, they found a tendency to lateralization of linguistic functions in the right hemisphere in children with autism.

\section{THE PERCEPTION OF MUSIC}

In contrast, data suggest a higher performance in many aspects of basic perception of music among people with autism (of course, not just in music). O'Riordan and Passetti /95/ showed superior auditory discrimination in people with autism relative to controls. Frith /29/ studied musical tones sequences produced by people with autism and also in disorder-free people and found that sequences were judged as of better quality in people with autism even if more rigid and stereotyped. Blackstock /6/ proved that people with autism preferred to hear a musical sound than a non-verbal one; they preferred to hear these two types of sounds with their left ear, whereas disorder-free people show right-ear preference to speech sounds. The group of children with autism studied by Applebaum and colleagues / $3 /$ imitated tones and series of tones as well as or even better than disorder-free people of the same age. Nakamura and colleagues /88/ suggested that adults with autism show right hemispheric dominance for music. Thaut /142/ assessed musical compositions done by people with autism and their responses were judged as less complex but more original.

The high-level people with autism studied by Plaisted and colleagues /108/ got higher marks than disorder-free people when discriminating very similar tones that they had never heard before. Heaton and colleagues /49/ showed that people with autism had a higher ability to identify a simple note. Mottron and colleagues /85/ studied QC's abilities, an 18 year-old adolescent with low-level autism, who shows special absolute pitch ability. Only one out of 10,000 people have absolute pitch (the ability to name exactly any heard note) and it is 
rare even among musicians. Active absolute pitch (the ability to produce any asked note exactly) is even rarer. Absolute pitch is much more common among people with autism, and among people with autism without absolute pitch their ability to discriminate sounds is higher than that of disorder-free people. QC also showed active absolute pitch and a high long-term memory (LTM) for music. Young and Nettelbeck /149/ studied the case of TR, a 12 year-old Australian boy with high-level autism, absolute pitch and an excellent memory for music.

Mottron and colleagues $/ 84 /$, in an excellent study, manipulated melodies on a local or global level. No differences were found when pinpointing global changes in melodies. However, people with autism showed better performance in local changes. These findings confirm the existence of a local bias in the musical perception of people with autism but they challenge the global deficit perception theory as regards music.

The people with autism of the group studied by Heaton and colleagues /48/ showed a better ability to differentiate small changes in melodies (from 1-4 semitones). No significant differences were found in global structures (3-note chords); this suggests normal holistic processing of music in people with autism. Their processing style would not mean any disadvantage with global musical material and remarkable advantages in subtle discrimination of small differences. Heaton /47/ showed that people with autism labeled tones better and also had a better tonal memory. They found a better chord segmentation of tones in people with autism if previously exposed to separate notes. However, no differences were found when disintegrating chords that had not been previously heard, as their performance did not depend on tone memory. This implies that both people with autism and disorderfree people perceived chords holistically.

Foxton and colleagues /28/ conclude that the perception of pitch variation in a melody is influenced by the variation of notes surrounding the target note both in people with autism and in disorder-free people. This result is particularly important, as it is the auditory equivalent to the better perception of hidden figures in visual modality $/ 22 /$ and it suggests that global/local processing peculiarities are not only visual. By using the modern statistical technique of signal detection analysis, Bonnel and colleagues /9/ show-ed higher tonal sensitivity in people with autism and an advantage in categorizing tones. As foreseen in the enhanced perceptual functioning model for peaks of ability in autism by Mottron and Burack /83/, people with autism show better performance in various low-level perception musical tasks.

Heaton and Wallace /46/ point out that autism (or autistic traits) and savant musical abilities are inseparably linked. The group of people with autism studied by Heaton /45/ showed a greater capacity for tone direction detection in small tonal intervals. No differences were found in the musical contours test. These findings confirm the hypothesis of the first studies which showed a better tonal processing and a non-altered capacity to represent structures that are very close in the musical scale among people with autism. Kellerman and Gorman /60/, in their review, reach the conclusion that musical auditory perception is better in people with autism. Moreover, the results of the pilot study of Reitman and Carlos Albizu $/ 113 /$ indicate that music therapy intervention can have positive out-comes and may be an effective method for increasing joint attention skills in some children with autism.

\section{DISCUSSION AND CONCLUSIONS}

There are experimental data suggesting that perceptive disturbances - auditory in particular should be included among the diagnostic criteria for autistic syndrome disorders. All patients diagnosed with autism suspected of hearing deficit should undergo audiometric screening so as to provide them with the necessary hearing aids. Such audiometric screening should be periodical owing to the higher risk of meddle ear diseases in people with autism.

The data on obligatory evoked potentials lead to the conclusion that there might be some genetic or acquired disorder in the brainstem processing struc-tures. The disturbances found in cognitive evoked potentials suggest alterations in auditory informa-tion processing, auditory identification, 
attentional processing and decision making in people with autism.

Neuroimaging studies have found evidence of anatomical and functional disturbances in the brainstem, the cerebellum and the temporal cortex, among other auditory structures. These disturbances in cortical auditory processing are involved in the language disorders and inadequate responses to sounds which are usually observed in autism. This suggests a different development of the auditory system in children with autism that may reflect disturbances in cortical maturational processes.

A great deal of research supports the idea of atypical hemispheric lateralization among people with autism. However, their performance in global perceptive aspects is the same as in disorder-free people. Responses to the human voice, mainly with emotional content, are altered and do not activate the same brain structures.

The most typical sensorial aspects of prosodic comprehension and production are altered in people with autism. Speech perception is altered among people with autism and is clearly hindered by the previously studied auditory alterations.

Experimental data support Ornitz's theory /100/ on sensorial modulation alterations due to genetic or acquired flaws in brainstem structures. They also support Damasio's theory /20/ on teleencephalic disorders. Both theories should be taken into consideration since disturbances in the brainstem can cause cortical alterations. The data clearly support the theory of Mottron and colleagues /84/ on local bias.

Neuroimaging experiments on the functional processing of musical stimuli should be designed. Research should be methodologically cautious as regards precise diagnosis; adequate control groups and distorting variable control. It is highly advisable to study people with autism free of intellectual or any other kind of associated disorder, as this would simplify the interpretation of the different studies. However, this last aspect is obviously difficult.

Important implications must be inferred to the design of adequate therapy for persons with autism. Their auditory alterations can interfere with therapy and should therefore always be taken into consideration.

\section{ACKNOWLEDGEMENTS}

The author thanks his friend and translator, Alejandro Diez-Huélamo.

\section{REFERENCES}

1. American Psychiatric Association. Diagnostic and Statistical Manual of Mental Disorders. DSM-III-R. ( $3^{\text {rd }}$ edn., rev.). Washington, DC: Author, 1987.

2. American Psychiatric Association. Diagnostic and Statistical Manual of Mental Disorders. DSM-III. (3rd edn.). Washington, DC: Author, 1980.

3. Applebaum E, Egel A, Koegel R, Imhoff B. Measuring musical abilities of autistic children. J Autism Dev Disord, 1979; 9: 279-285.

4. Baltaxe C, Guthrie D. The use of primary sentence stress by normal, aphasic, and autistic children. J Autism Dev Disord, 1987; 17: 255-271.

5. Belin P, Zatorre RJ, Lafaille P, Ahad P. Pike B. Voice-selective areas in human auditory cortex. Nature, 2000; 403: 309-312.

6. Blackstock EG. Cerebral asymmetry and the development of early infantile autism. J Autism Child Schizophr, 1978; 8: 339-353.

7. Boddaert $\mathrm{N}$, Chabane $\mathrm{N}$, Belin $\mathrm{P}$, Bourgeois $\mathrm{M}$, Royer V, Barthélémy C, Mouren-Simeoni MC, Philippe A, Brunelle F, Samson Y, Zilbovicius M. Perception of complex sounds in autism: abnormal auditory cortical processing in children. Am J Psychiatry, 2004; 161: 2117-2120.

8. Boddaert N, Belin P, Chabane N, Poline JB, Barthélémy C, Mouren-Simeoni MC, Brunelle F, Samson Y, Zilbovicius M. Perception of Complex Sounds: Abnormal Pattern of Cortical Activation in Autism. Am J Psychiatry, 2003; 160: 2057-2060.

9. Bonnel AC, Mottron L, Peretz I, Trudel M, Gallum E, Bonnel AM. Enhanced sensitivity for pitch in individuals with autism: A Signal Detection Analysis. J Cogn Neurosci, 2003; 15: 226-235.

10. Boucher J, Lewis V, Collis GM. Voice processing abilities en children with autism, children with specific language impairments, and young typically developing children. J Child Psychol Psychiatry, 2000; 41: 847-857.

11. Boucher J, Lewis V, Collis GM. Familiar face and voice matching and recognition in children with autism. J Child Psychol Psychiatry, 1998; 39: 171181.

12. /12/ Bruneau N, Roux S, Adrien JL, Barthélémy C. Auditory associative cortex dysfunction in children with autism: evidence from late auditory evoked 
potentials (N1 wave-T complex). Clin Neurophysiol, 1999; 110: 1927-1934.

13. Bruneau N, Dourneau MC, Garreau B, Porcelot L. Blood flow response to auditory stimulations in normal, mentally retarded, and autistic children: A preliminary Transcraneal Doppler ultrasonographic study of the middle cerebral arteries. Biol Psychiatry, 1992; 32: 691-699.

14. Bruneau N, Garreau B, Roux S, Lelord G. Modulation of auditory evoked potentials with increasing stimulus intensity in autistic children. Electroenceph clin Neurophysiol, 1987; Supplement, 40: 584-589.

15. Ceponiéne R, Lepistö T, Shestakova S, Vanhala R, Alku P, Näätänen R, Yaguchi K. Speech-soundselective auditory impairment in children with autism: they can perceive but do not attend. Proc Natl Acad Sci U S A, 2003; 100: 5567-5572.

16. Collet L, Rogé B, Descouens D, Moron P, Duverdy $\mathrm{F}$, Urgell $\mathrm{H}$. Objective auditory dysfunction in infantile autism. Lancet, 1993; 342: 923-924.

17. Courchesne E, Courchesne RY, Hicks G, Lincoln AJ. Functioning of the brain-stem auditory pathway in non-retarded autistic individuals. Electroenceph clin Neurophysiol, 1985; 61: 491-501.

18. Courchesne E, Lincoln AJ, Kilman BA, Galambos R. Event-related brain potential correlates of the processing of novel visual and auditory information in autism. J Autism Dev Disord, 1985; 15: 55-76.

19. Courchesne E, Kilman BA, Galambos R, Lincoln AJ. Autism: Processing of novel auditory information assessed by event related brain potentials. Electroenceph clin Neurophysiol, 1984; 59: 238-248.

20. Damasio A, Maurer RG. A neurological model for childhood autism. Arch Neurol, 1978; 35: 777-786.

21. Dawson G, Finley C, Phillips S, Galpert L, Lewy A. Reduced P3 Amplitude of the Event-Related Brain Potential: Its Relationship to Language Ability in Autism. J Autism Dev Disord, 1988; 18: 493-504.

22. de Jonge M V, Kemner C, van Engeland H. Superior Disembedding Performance of High-Functioning Individuals with Autism Spectrum Disorders and Their Parents: The Need for Subtle Measures. J Autism Dev Disord, 2006; 36: 677-683.

23. Dunn M, Vaughan H. Jr., Kreuzer J, Kurtzberg D. Electrophysiologic correlates of semantic classification in autistic and normal children. Dev Neuropsychol, 1999; 16: 79-99.

24. Faro MD, Windle WF. Transneuronal degeneration in brains of monkeys asphyxiated at birth. Exp Neurol, 1969; 24: 38-53.

25. Fein D, Skoff B, Mirsky AF. Clinical correlates of brainstem dysfunction in autistic children. J Autism Dev Disord, 1981; 11: 303-315.
26. Fine J, Bartolucci G, Ginsberg G, Szatmari P. The use of intonation to communicate in pervasive developmental disorders. J Child Psychol Psychiatry, 1991; 32: 771-782.

27. Flagg EJ, Cardy JE, Roberts W, Roberts TP. Language lateralization development in children with autism: insights from the late field magnetoencephalogram. Neurosci Lett, 2005; 386: 82-87.

28. Foxton JM, Stewart ME, Barnard L, Rodgers J, Young AH, O'Brien G, Griffiths TD. Absence of auditory "global interference" in autism. Brain, 2003; 126: 2703-2709.

29. Frith U. Cognitive mechanisms in autism: Experiments with color and tone sequence production. J Autism Child Schizophr, 1972; 2: 160173.

30. Frith U. Studies in pattern detection in normal and autistic children. I. Immediate recall of auditory sequences. J Abnorm Psychol, 1970; 76: 413-420.

31. Gage NM, Siegel B, Callen M, Roberts TP. Cortical sound processing in children with autism disorder: an MEG investigation. Neuroreport, 2003; 14: $2047-$ 2051.

32. Gage NM, Siegel B, Roberts TP. Cortical auditory system maturational abnormalities in children with autism disorder: an MEG investigation. Brain Res Dev Brain Res, 2003; 144: 201-209.

33. Garreau B, Zilbovicius M, Guerin P, Samson Y, Syrota A, Lelord G. Effects of auditory stimulation on regional cerebral blood flow in autistic children. Dev Brain Dysfunct, 1994; 7: 119-128.

34. Gayda M, Saleh D. Surdité périphérique, surdité centrale, surdité psychique: les difficultés diagnostiques chez l'enfant autiste. Rev laryngol otol rhinol, 2004; 125: 277-280.

35. Gersten R. Stimulus overselectivity in autistic, trainable, mentally retarded, and non-handicapped children: Comparative research controlling chronological (rather than mental) age. J Abnorm Child Psychol, 1983; 11: 61-76.

36. Gervais H, Belin P, Boddaert N, Leboyer M, Coez A, Barthélémy C, Samson Y, Zilbovicius M. Abnormal Voice Processing in Autism: a fMRI study. Nat Neurosci, 2004; 7: 801-802.

37. Gillberg C, Rosenhall U, Johansson E. Auditory brainstem responses in childhood psychosis. J Autism Dev Disord, 1983; 13: 181-195.

38. Gomot M, Giard MH, Adrien JL, Barthélémy C, Bruneau N. Hypersensitivity to acoustic change in children with autism: Electrophysiological evidence of left frontal cortex dysfunctioning. Psychophysiology, 2002; 39: 577. 
39. Gravel JS, Dunn M, Lee WW, Ellis MA. Peripheral audition of children on the autistic spectrum. Ear Hear, 2006; 27: 299-312.

40. Grewe TS, Danhauer JL, Danhauer KJ, Thornton AR. Clinical Use of Otoacoustic Emissions in Children with Autism. Int J Pediatr Otorhinolaryngol, 1994; 30: 123-132.

41. Grillon C, Courchesne E, Akshoomoff N. Brainstem and middle latency auditory evoked potentials in autism and developmental language disorder. J Autism Dev Disord, 1989; 19: 255-269.

42. Gunji A, Koyama S, Senju A, Sekiguchi T, Tojo Y, Kaga M. Auditory feedback in children with autism: A reduced Lombard effect. Neurosci Res, 2006; 55: S134-S134 Suppl. 1.

43. Hashimoto T, Tayama M, Murakawa K, Yoshimoto T, Miyazaki M, Harada M, Kuroda Y. Development of the brainstem and cerebellum in autistic patients. $\mathrm{J}$ Autism Dev Disord, 1995; 25: 1-18.

44. Hayes RW, Gordon AG. Auditory abnormalities in autistic children. Lancet, 1977; 310: 767.

45. Heaton P. Interval and Contour Processing in Autism. J Autism Dev Disord, 2005; 35: 787-793.

46. Heaton P, Wallace GL. Annotation: The savant syndrome. J Child Psychol Psychiatry, 2004; 45 : 899-911.

47. Heaton P. Pitch memory, labelling and disembedding in autism. J Child Psychol Psychiatry, 2003; 44: 543551.

48. Heaton P, Pring L, Hermelin B. Musical Processing in High Functioning Children with Autism. Ann N Y Acad Sci, 2001; 930: 443-444.

49. Heaton P, Hermelin B, Pring L. Autism and pitch processing: A precursor for savant musical ability? Music Percept, 1998; 15: 291-305.

50. Hermelin B, Frith U. Psychological studies of childhood autism: can autistic children make sense of what they see and hear? J Spec Educ, 1971; 5: 107117.

51. Hobson RP, Ouston J, Lee A. Naming emotion in faces and voices: Abilities and disabilities in autism and mental retardation. Brit J Dev Psychol, 1989; 7 : 237-250.

52. Hobson RP, Ouston J, Lee A. Emotion recognition in autism: Coordinating faces and voices. Psychol Med, 1988; 18: 911-923.

53. James AL, Barry RJ. Developmental effects in the cerebral lateralization of autistic, retarded and normal children. J Autism Dev Disord, 1983; 13: 43-54.

54. Jansson-Verkasalo E. Auditory event-related potentials as indices of language impairment in children born preterm and with Asperger syndrome. Helsinki: Oulu University Press, 2003.

55. Jansson-Verkasalo E, Kujala T, Jussila K, Mattila ML, Moilanen I, Näätänen R, Suominen K,
Korpilahti P. Similarities in the phenotype of the auditory neural substrate in children with Asperger syndrome and their parents. Eur J Neurosci, 2005; 22: 986-990.

56. Jansson-Verkasalo E, Ceponiene R, Kielinen M, Suominen K, Jäntti V, Linna SL, Moilanen I, Näätänen R. Deficient auditory processing in children with Asperger Syndrome, as indexed by event-related potentials. Neurosci Lett, 2003; 338: 197-200.

57. Jure R, Rapin I, Tuchman RF. Hearing impaired autistic children. Dev Med Child Neurol, 1991; 33: 1062-1072.

58. Kanner L. Autistic disturbances of affective contact. Nerv Child, 1943; 2: 217-250.

59. Kasai K, Hashimoto O, Kawakubo Y, Yumoto M, Kamio S, Itoh K, Koshida I, Iwanami A, Nakagome K, Fukuda M, Yamasue H, Yamada H, Abe O. Aoki S, Kato N. Delayed automatic detection of change in speech sounds in adults with autism: a magnetoencephalographic study. Clin Neurophysiol, 2005; 116: 1655-1664.

60. Kellerman GR, Gorman JM. Auditory abnormalities in autism: toward functional distinctions among findings. CNS Spectr, 2005; 10: 748-756.

61. Kemner C, Verbaten MN, Cuperus JM, Camfferman G, van Engeland H. Auditory event-related brain potentials in autistic children and three different control groups. Biol Psychiatry, 1995; 38: 150-165.

62. Kern JK, Trivedi MH, Garver CR, Grannemann BD, Andrews AA, Savla JS, Johnson DG, Mehta JA, Schroeder JL. The pattern of sensory processing abnormalities in autism. Autism, 2006; 10: 480-494.

63. Khalfa S, Bruneau N, Rogé B, Georgieff N, Veuillet E, Adrien JL, Barthélémy C, Mollet L. Peripheral auditory asymmetry in infantile autism. Eur $\mathbf{J}$ Neurosci, 2001; 13: 628.

64. Klin A. Auditory brainstem responses in autism: brainstem dysfunction or peripheral hearing loss? J Autism Dev Disord, 1993; 23: 15-35.

65. Klin A. Young autistic children's listening preferences in regard to speech: a possible characterization of the symptom of social withdrawal. J Autism Dev Disord, 1991; 21: 29-42.

66. Koegel RL, Schreibman L. Identification of consistent responding to auditory stimuli by a functionally deaf autistic child. J Autism Child Schizophr, 1976; 6: 147-156.

67. Landau WM, Freygang WH, Rowland LP, Sokoloff L, Kety SS. The local circulation of the living brain; values in the unanesthetized and anesthetized cat. Trans Am Neurol Assoc, 1955-1956; 80th Meeting:125-129.

68. Lepistö T, Kujala T, Vanhala R, Alku P, Huotilainen M, Näätänen R. The discrimination of and orienting 
to speech and non-speech sounds in children with autism. Brain Res, 2005; 1066: 147-157.

69. Lincoln AJ, Courchesne E. Sensory modulation of auditory stimuli in children with autism and receptive developmental language disorder: event-related brain potential evidence. J Autism Dev Disord, 1995; 25: 521.

70. Loveland KA, Tunali-Kotoski B, Chen YR, Ortegon J, Pearson DA, Brelsford KA, Gibbs MC. Emotion recognition in autism: verbal and nonverbal information. Dev Psychopathol, 1997; 9: 579-593.

71. Loveland KA, Tunali-Kotoski B, Chen YR, Ortegon J, Pearson DA, Brelsford KA, Gibbs MC. Intermodal perception of affect in persons with autism or Down syndrome. Dev Psychopathol, 1995; 7: 409-418.

72. Martineau J, Roux S, Garreau B, Adrien JL, Lelord G. Unimodal and crossmodal reactivity in autism: presence of auditory evoked potentials. Biol Psychiatry, 1992; $31:$ 1190-1203.

73. Martineau J, Garreau B, Roux S, Lelord G. Auditory evoked responses and their modifications during conditioning paradigm in autistic children. J Autism Dev Disord, 1987 ; 17: 525-540.

74. Martineau J, Garreau B, Barthélémy C. Evoked potentials and P300 during sensory conditioning in autistic children. Ann N Y Acad Sci, 1984 ; 425: 362369.

75. Martineau J, Laffont F, Bruneau N, Roux S, Lelord G. Event-related potentials evoked by sensory stimulation in normal mentally retarded and autistic children. Electroenceph clin Neurophysiol, 1980; 48: 140-153.

76. Maziade M, Merette C, Cayer M, Roy MA, Szatmari $\mathrm{P}$, Cote R, Thivierge J. Prolongation of brainstem auditory-evoked responses in autistic probands and their unaffected relatives. Arch Gen Psychiat, 2000; 57: 1077-1083.

77. McCann J, Peppé S. Prosody in autism spectrum disorders: a critical review. Int J Lang Comm Dis, 2003; 38: 325-350.

78. McClelland RJ, Watson D, McAllister HG, Lumsden J. Infantile autism and the brain-stem auditory evoked potentials. Electroenceph clin Neurophysiol, 1986; 63: 79P-80P

79. Metz JR. Stimulation preferences of autistic children. J Abnorm Psychol, 1967; 72: 529-535.

80. Møller AR, Kern JK, Grannemann B. Are the nonclassical auditory pathways involved in autism and PDD? Neurol Res, 2005; 27: 625-629.

81. Moore JK, Perazzo LM, Braun A. Time course of axonal myelination in the human brainstem auditory pathway. Hear Res, 1995; 87: 21-31.

82. Mottron L. L'autisme: une autre intelligence. Diagnostic, cognition et support des personnes autistes sans déficience intellectuelle. Bruxelles: Mardaga, 2004.

83. Mottron L, Burack J. Enhanced perceptual functioning in the development of autism. In Burack JA, Charman T, Yirmiya N, Zelazo PR (Eds.), The development of autism: Perspectives from theory and research. Mahwah, N. J.: Erlbaum, 2001, 131-148.

84. Mottron L, Peretz I, Ménard E. Local and global processing of music in high-functioning persons with autism. J Child Psychol Psychiatry, 2000; 41: 10571068.

85. Mottron L, Peretz I, Belleville S, Rouleau N. Absolute pitch in autism: A case study. Neurocase, 1999; 5: 485-502.

86. Müller RA, Behem ME, Rothermel RD, Chugani DC, Muzik O, Mangner TJ, Chugani HT. Brain Mapping of Language and Auditory Perception in HighFunctioning Adults: A PET Study. J Autism Dev Disord, 1999; 29: 19-32.

87. Myers RE. Two patterns of perinatal brain damage and their conditions of occurrence. Am J Obstet Gynecol, 1972; 112: 246-276.

88. Nakamura K, Toshima T, Takemura I. The comparative and developmental study of auditory information processing in autistic adults. J Autism Dev Disord, 1986; 16: 105-118.

89. Niwa S, Ohta M, Yamazaki K. P300 and stimulus evaluation process in autistic subjects. J Autism Dev Disord, 1983; 13: 33-42.

90. Novick B, Vaughan HG Jr, Kurtzberg D, Simson R. An Electrophysiologic indication of auditory processing defects in autism. Psychiat Res, 1980; 3: 107-114.

91. Novick B, Kurtzberg D, Vaughan HG Jr. An Electrophysiologic indication of defective information storage in childhood autism. Psychiat Res, 1979; 1: 101-108.

92. Oades RD, Walker MK, Geffen LB, Stern LM. Event-related potentials in autistic and healthy children on an auditory choice reaction time task. Int J Psychophysiol, 1988; 6: 25-37.

93. Oram-Cardy JE, Flagg EJ, Roberts W, Roberts TP. Delayed mismatch field for speech and non-speech sounds in children with autism. Neuroreport, 2005; 16; 521-525.

94. Oram-Cardy JE, Ferrari P, Flagg EJ, Roberts W, Roberts TPL. Prominence of M50 auditory evoked response over M100 in childhood and autism. Neuroreport, 2004; 15: 1867-1870.

95. O'Riordan M, Passetti F. Discrimination in autism within different sensory modalities. J Autism Dev Disord, 2006; 36: 665-675.

96. Ornitz EM. Autism at the interface between sensory and information processing. In: G. Dawson (Ed.), 
Autism, New perspectives on diagnosis, nature and treatment. New York: Guilford, 1989, 174-207.

97. Ornitz EM. Autism: A disorder of directed attention. Brain Dysfunction, 1988; 1: 309-322.

98. Ornitz EM. Neurophysiology of infantile autism. J Am Acad Child Psychiatry, 1985; 24: 251-262.

99. Ornitz EM. The modulation of sensory input and motor output in autistic children. J Autism Child Schizophr, 1974; 4: 197-215.

100. Ornitz EM. The disorders of perception common to early infantile autism and schizophrenia. Compr Psychiatry, 1969; 10: 259-274.

101. Ornitz EM, Atwell CW, Kaplan AR, Westlake JR. Brain-stem dysfunction in autism. Arch Gen Psychiatry, 1985; 42: 1018-1025.

102. Ornitz EM, Guthrie D, Farley AJ. The early symptoms of childhood autism. In: G. Serbam (Ed.) Cognitive defects in the development of mental illness. New York: Brunner/Mazel, Inc., 1978.

103. Ornitz EM, Walter DO. The effect of sound pressure waveform on human brain stem auditory evoked responses. Brain Res, 1975; 92: 490-498.

104. Ornitz EM, Forsythe AB, Tanguay PE, Ritvo ER, De la Peña A, Ghahremani J. The recovery cycle of the averaged auditory evoked response during sleep in autistic children. Electroenceph clin Neurophysiol, 1974; 37: 173-174.

105. Ornitz EM, Tanguay PE, Lee JCM. The effect of stimulus interval in the auditory evoked response during sleep in autistic children. J Autism Child Schizophr, 1972; 2: 140-150.

106. Ornitz EM, Ritvo ER, Panman LE, Lee YH, Carr EM, Walter RD. The auditory evoked response in normal and autistic children during sleep. Electroenceph clin Neurophysiol, 1968; 25: 221-230.

107. Paul R, Augustyn A, Klin A, Volkmar F. Perception and Production of Prosody by Speakers with Autism Spectrum Disorders. J Autism Dev Disord, 2005; 35: 205-220.

108. Plaisted K, O’Riordan M, Baron-Cohen S. Enhanced discrimination of novel, highly similar stimuli by adults with autism during a perceptual learning task. J Child Psychol Psychiatry, 1998; 39: 765-775.

109. Prior MR, Bradshaw JL. Hemisphere functioning in autistic children. Cortex, 1979; 15: 73-81.

110. Ranck JB, Windle WF. Brain damage in the monkey, Macaca mulatta, by asphyxia neonatorum. Exp Neurol, 1959; 1: 130-154.

111. Rapin I, Dunn M. Update on the language disorders of individuals on the autistic spectrum. Brain DevJpn, 2003; 25: 166-172.

112. Reitman MR. Carlos Albizu U. Effectiveness of music therapy interventions on joint attention in children diagnosed with autism: A pilot study.
Dissertation Abstracts International: Section B: The Sciences and Engineering, 2006; 66: 6315.

113. Reynolds BS, Newsom CD, Lovaas OI. Auditory overselectivity in autistic children. J Abnorm Child Psychol, 1974; 2: 253-256.

114. Ricks D. Vocal communication in pre-verbal normal and autistic children. In O'Connor N. (Ed.), Language, cognitive deficits, and retardation. London: Butterworths, 1975, 245-268.

115. Ritvo ER, Freeman BJ. National Society for Autistic Children definition syndrome of autism. J Autism Child Schizophr, 1978; 8: 162-167.

116. Rogers SJ, Ozonoff S. Annotation: What do we know about sensory dysfunction in autism? A critical review of the empirical evidence. J Child Psychol Psyc, 2005; 46: 1255-1268.

117. Rosenblum SM, Arick JR, Krug DA, Stubbs EG, Young NB, Pelson RO. Auditory brainstem evoked responses in autistic children. J Autism Dev Disord, 1980; 10: 215-225.

118. Rosenhall U, Nordin V, Brantberg K, Gillberg C. Autism and auditory brain stem responses. Ear Hear, 2003; 24: 206-214.

119. Rosenhall U, Nordin V, Sandstrom M, Ahlsen G, Gillberg C. Autism and Hearing Loss. J Autism Dev Disord, 1999; 29: 349-357.

120. Rumsey JM, Grimes AM, Pikus AM, Duara R, Ismond DR. Auditory brainstem responses in pervasive developmental disorders. Biol Psychiatry, 1984; 19: 1403-1418.

121. Rutherford, MD, Baron-Cohen S, Wheelwright S. Reading the Mind in the Voice: A Study with Normal Adults and Adults with Asperger Syndrome and High Functioning Autism. J Autism Dev Disord, 2002; 32: 189-194.

122. Seri S, Cerquiglini A, Pisani F, Curatolo P. Autism in tuberous sclerosis: evoked potential evidence for a deficit in auditory sensory processing. Clin Neurophysiol, 1999; 110: 1825-1830.

123. Sersen E, Heaney G, Clausen J, Belser R. Brainstem auditory-evoked responses with and without sedation in autism and Down's syndrome. Biol Psychiatry, 1990; 27: 834-840.

124. Sheinkopf SJ, Mundy PD, Oller K, Steffens M. Vocal Atypicalities of Preverbal Autistic Children. J Autism Dev Disord, 2000; 30: 345-354.

125. Shriberg LD, Paul R, McSweeny JL, Klin AM, Cohen DJ, Volkmar FR. Speech and prosody characteristics of adolescents and adults with highfunctioning autism and Asperger syndrome. J Speech Lang Hear Res, 2001; 44: 1097-1115.

126. Simon N. The auditory system, brain maturation, and development in autistic children. J Autism Dev Disord, 1999; 29: 94-95. 


\section{P.L. NIETO DEL RINCÓN}

127. Simon N. Echolalic speech in childhood autism. Arch Gen Psychiatry, 1975; 32: 1439-1446.

128. Skoff BF, Fein D, McNally B, Lucci D, HumesBartlo NM, Waterhouse L. Brainstem auditory evoked potentials in autism. Psychophysiology, 1986; 23: 462.

129. Skoff BF, Mirsky AF, Turner D. Prolonged brainstem transmission time in autism. Psychiatry Res, 1980; 2: 157-166.

130. Smith DEP, Miller SD, Stewart M, Walker TL, McConnell JV. Conductive Hearing Loss in Autistic, Learning Disabled, and Normal Children. J Autism Dev Disord, 1988; 18: 53-66.

131. Sohmer H, Student MS. Auditory nerve and brainstem evoked response in normal, autistic, minimal brain dysfunction and psychomotor retarded children. Electroenceph clin Neurophysiol, 1978; 44, 380-388.

132. Sokoloff L. Localization of functional activity in the central nervous system by measurement of glucose utilization with radioactive deoxyglucose. J Cereb Blood Flow Metab, 1981; 1: 7-36.

133. Strata F, Delpolyi AR, Bonham BH, Chang EF, Liu RC, Nakahara H, Merzenich MM. Perinatal anoxia degrades auditory system function in rats. Proc Natl Acad Sci U S A., 2005; 102: 19156-19161.

134. Student MSH, Sohmer H. Erratum. J Autism Dev Disord, 1979; 9: 309.

135. Student MSH, Sohmer H. Evidence from auditory nerve and brainstem evoked responses for an organic brain lesion in children with autistic traits. J Autism Child Schizophr, 1978; 8: 13-20.

136. Tanguay PE, Edwards RM, Buchwald J, Schwafel J, Allen V. Auditory brainstem evoked responses in autistic children. Arch Gen Psychiatry, 1982; 39: 174-180.

137. Tas A, Yagiz R, Tas M, Esme M, Uzun C, Karasalihoglu AR. Evaluation of hearing in children with autism by using TEOAE and ABR. Autism, 2007; 11: 73-79.

138. Taylor MJ, Rosenblatt B, Linschoten L. Auditory brainstem response abnormalities in autistic children. Can J Neurol Sci, 1982; 9: 429-433.

139. Tecchio F, Benassi F, Zappasodi F, Gialloreti LE, Palermo M, Seri S, Rossini PM. Auditory Sensory Processing in Autism: A Magnetoencephalographic Study. Biol Psychiatry, 2003; 54: 647-654.
140. Teder-Sälejärvi WA, Pierce KL, Courchesne E, Hillyard SA. Auditory spatial localization and attention deficits in autistic adults. Brain Res Cogn Brain Res, 2005; 23: 221-234.

141. Tharpe AM, Bess FH, Sladen DP, Schissel H, Couch S, Schery T. Auditory characteristics of children with autism. Ear Hear, 2006; 27: 430-441.

142. Thaut M. Measuring Musical Resposiveness in Autistic Children A Comparative Analysis of Improvised Musical Tone Sequences of Autistic, Normal and Mentally Retarded Individuals. J Autism Dev Disord, 1988; 18: 561-572.

143. Thivierge J, Bedard C, Cote R, Maziade M. Brainstem auditory evoked response and subcortical abnormalities in autism. Am J Psychiatry, 1990; 147: 1609-1613.

144. VanLancker-Sitdis D, Cornelius C, Kreiman J. Recognition of emotional-prosodic meanings in speech by autistic, schizophrenic and normal children. Dev Neuropsychol, 1989; 5: 207-226.

145. Wang AT, Lee SS, Sigman M, Dapretto M. Neural basis of irony comprehension in children with autism: the role of prosody and context. Brain, 2006; 129: 932-943.

146. Wetherby AM, Koegel RL, Mendel M. Central auditory nervous system dysfunction in echolalic autistic individuals. J Speech Hear Res, 1981; 24: 420-429.

147. Wong V, Wong SN. Brainstem auditory evoked potential study in children with autistic disorder. $\mathbf{J}$ Autism Dev Disord, 1991; 21: 329-340.

148. Xi CY, Ma HW, Zhao YR, Zhao YJ, Hua TY. Analysis of Abnormal Sensory Behaviors of Autism Children. Chin J Clin Psychol, 2006; 14: 266-267.

149. Yakovlev PI, Lecours AR. The myelogenetic cycles of regional maturation of the brain. In Minkowski A. (Ed.), Regional Development of the Brain in Early Life Oxford: Blackwell Scientific Publications, 1967, 3-70.

150. Young RL, Nettelbeck T. The Abilities of a Musical Savant and His Family J Autism Dev Disord, 1995; 25: 231-248. 